\title{
Including the blind community in precision medicine research: findings from a national survey and recommendations
}

\author{
Maya Sabatello, LLB, PhD (i) ${ }^{1}$, Lou Ann Blake, JD², Audrey Chao, BA (i) ${ }^{3}$, Arielle Silverman, $\mathrm{PhD}^{4}$, \\ Ronit Ovadia Mazzoni, MS ${ }^{5}$, Yuan Zhang, MS, $\mathrm{MA}^{6}$, Ying Chen, MD, $\mathrm{MS}^{7}$ and \\ Paul S. Appelbaum, MD ${ }^{8}{ }^{8}$
}

Purpose: Despite ongoing efforts to increase diversity of cohorts in precision medicine research (PMR), little is known about the obstacles to inclusion of blind people and those with low vision ("the blind community") in PMR. The blind community comprises $\sim 10 \%$ of the US adult population and its members commonly experience health disparities. Understanding barriers to inclusion of this community is necessary to facilitate their participation.

Methods: An online survey was developed in disability-accessible formats. Key questions included views on PMR; willingness to participate, provide data, and engage in the study; data sharing and consent; and perceived barriers to participation. Analyses describe results for all participants.

Results: Two hundred seventy-one blind/low-vision participants completed the survey. Participants expressed strong support for $\mathrm{PMR}$, and willingness to participate in PMR, to provide lifestyle, biological and medical information, to engage with the study, and to have their data shared with other researchers. Preferences for data sharing and consent models varied. Significantly, $65 \%$ identified 3-6 barriers to participation, particularly inaccessible transportation, clinics, and facilities; inaccessible information; and attitudinal and institutional barriers.

Conclusion: Removing the identified barriers is key. Measures that could increase inclusivity of blind people and those with low vision in PMR are suggested.

Genetics in Medicine (2019) 21:2631-2638; https:/doi.org/10.1038/s41436019-0533-y

Keywords: blind and low-vision individuals; disability; precision medicine research; barriers; inclusion and accessibility measures

\section{INTRODUCTION}

Precision medicine research (PMR) is an emerging approach for health care, aimed at developing prevention, diagnosis, and treatment options tailored to an individual's genetics, environment, and lifestyle choices. PMR has gained momentum in the United States with the launch of the All of Us Research Program (AoU), which seeks to enroll, collect a range of data from, and engage with one million Americans. ${ }^{1}$ Because the stakes of exclusion are high-communities underrepresented in PMR cohorts will not accrue the benefits of this research - the National Institutes of Health (NIH) have dedicated tremendous efforts to include historically marginalized racial and ethnic minorities in PMR. However, people with disabilities have not received much attention in planning PMR. This omission is concerning: as a group, people with disabilities experience significant health disparities. ${ }^{2}$
Moreover, PMR initiatives that fail to address inclusion barriers in their early phases give the impression that certain populations are less valuable than others, with significant implications for whose interests will be considered in developing and implementing PMR studies. ${ }^{3}$

Blind people and those with low vision ("the blind community") are one subgroup of people with disabilities who could both benefit and are at risk of being excluded from PMR. Blindness and vision loss are among the most common adult medical conditions in the United States, ${ }^{4}$ encompassing an estimated 21 million people $(\sim 10 \%$ of the adult population), ${ }^{5}$ of whom $\sim 2.8 \%$ are legally blind or have trouble seeing even with corrective lenses ("low vision"). ${ }^{6}$ This population is projected to surge in the coming decades due to population aging and increased survival rates among people with chronic conditions that impact vision (e.g., diabetes). ${ }^{7}$ Moreover,

\footnotetext{
${ }^{1}$ Center for Research on Ethical, Legal \& Social Implications of Psychiatric, Neurologic \& Behavioral Genetics, Department of Psychiatry, Columbia University, New York, NY, USA; ${ }^{2}$ National Federation of the Blind, Baltimore, MD, USA; ${ }^{3}$ Columbia Law School and Columbia School of Social Work, New York, NY, USA; ${ }^{4}$ Disability Wisdom Consulting, Alexandria, VA, USA; ${ }^{5}$ Santa Clara Valley Medical Center, San Jose, CA, USA; ${ }^{6}$ Department of Biostatistics, Mailman School of Public Health, Columbia University, New York, NY, USA; ${ }^{7}$ New York State Psychiatric Institute, New York, NY, USA; ${ }^{8}$ Center for Research on Ethical, Legal \& Social Implications of Psychiatric, Neurologic \& Behavioral Genetics, Department of Psychiatry, Columbia University, New York, NY, USA. Correspondence: Maya Sabatello (ms4075@columbia.edu)
} 
blind people have a higher rate of chronic conditions such as hypertension and heart conditions compared with sighted people. ${ }^{8}$ Insofar as PMR could offer preventive and therapeutic opportunities for blind people, PMR inclusion will be key for them to reap the benefits.

The blind community's views on biomedical research are understudied but raise unique issues. Medicine in general, including genetic research, has operated under a model that focuses on curing or ameliorating physical and other impairments, and tends to view life with disabilities as unsatisfying. Although these views have been contested by disability communities, including the blind community, ${ }^{9}$ they have remained prevalent in society, and particularly in medical and research settings. ${ }^{10}$ Most notoriously, the eugenics movement in the early 20th century in the United States (and elsewhere), with its focus on eliminating and preventing reproduction of those who were deemed "genetically unfit," led to the forced sterilization of Americans with disabilities and later to mass euthanasia of people with disabilities in Nazi Germany. ${ }^{11}$ This history may evoke concerns that the genomic component of PMR will replicate historical wrongs.

Conversely, studies of patients with inherited vision conditions found support for diagnostic and predictive genetic testing. The strongest motivating factors were the possibility of identifying a novel treatment, understanding the cause of their visual disability, and confirming the inheritance of their condition, though most stated that they would not support pregnancy termination on this basis. ${ }^{12,13}$ Support for genetic research similarly can be found in NIH's eyeGENE ${ }^{\circledast}$ initiative, a repository for DNA that includes $>6400$ records of patients with rare inherited eye diseases (https://eyegene.nih. gov/). While informative, there are several reasons why these findings may not completely apply to PMR. First, PMR's exploratory goals do not necessarily focus on particular impairments, and thus require willingness to participate in scientific research that may not yield a diagnosis or intervention for one's own condition. Second, PMR requires not only one-time biospecimen collection but also other environmental and lifestyle information, thus raising concerns about privacy. Third, successful PMR requires long-term engagement-and thus also more time investment-by research participants.

We report findings from a national survey exploring the views of the blind community about participation and barriers to participation in PMR. This is a part of a larger study that included people with various disabilities $(n=1294)$. By focusing on blind/low-vision people, this article seeks to highlight the views and concerns of this group, and to offer tailored suggestions for developing PMR that is inclusive of the blind community.

\section{MATERIALS AND METHODS}

\section{Study design, procedures, and survey}

The methods and data collected for this study are detailed elsewhere. ${ }^{14}$ In brief, we conducted a national, Internet-based survey of people with disabilities to explore their views on PMR. The survey described a hypothetical national PMR cohort study (Appendix A), including information about PMR, key terms (e.g., genetics), and what participation in PMR might entail (e.g., data collection, access to their health information). Survey questions probed participants' views about PMR; most relevant for this paper are whether PMR should be conducted, and respondents' willingness to participate, to provide various types of data, and to engage in specific aspects of the study, along with their views about data sharing and consent, and perceived barriers to participation. Demographic data were collected. Most questions had dichotomized (yes/no) or predefined response options; questions about barriers to participation included an open-ended option.

The study was conducted in collaboration with several national organizations of persons with disabilities: the National Federation of the Blind (NFB), the Association of University Centers on Disabilities (AUCD), the National Council on Independent Living (NCIL), the National Association of the Deaf (NAD), and the American Association of Health and Disability (AAHD). People with disabilities, including blind people, were consulted about the survey's wording and accessible format and programming to ensure that the survey could be "read" by screen readers (or text-to-read programs). The national organizations circulated the invitation and a link to participate in the study through their listservs. Given this recruitment method, it was impossible to assess response rate. The survey was available in English, Spanish, and American Sign Language (as translated by the NAD), hosted by SurveyMonkey, and estimated to take 17 minutes to complete. Participants were offered a $\$ 25$ gift card. The institutional review board (IRB) at the New York State Psychiatric Institute approved the study.

For this paper, eligibility criteria for the primary study population were being at least 18 years old and identifying as blind or having low vision as a primary disability. Participants provided consent online and were required to answer correctly two questions about the study's purpose to access the survey.

\section{Statistical analysis}

All statistical analyses were performed with SAS 9.4 software. Demographic characteristics were reported as counts and percentages. Chi-square $\left(\chi^{2}\right)$ tests were used for categorical variables to compare differences among groups. Linear regression was conducted for total number of barriers (a continuous variable). Covariates were collapsed and recoded when data cells were small to reduce the number of categories for analysis.

\section{RESULTS}

\section{Study population}

Of the 1294 participants with disabilities in the study, 271 identified as blind or with low vision as a primary condition, including 30\% who reported multiple disabilities (e.g., autism, 
physical disabilities); $52.7 \%$ were female, $45.2 \%$ male, and $2.1 \%$ identified as nonbinary sex. Most participants were White $(80 \%)$ and employed full or part time (58\%). A minority completed high school/GED or less (15\%). Only $14 \%$ reported $<\$ 20,000$ household income (national poverty line is $<\$ 24,000 /$ family of four ${ }^{15}$ ). The demographic characteristics of survey respondents are presented in Table $\mathbf{1 .}$

Table 1 Demographic characteristics of blind/low-vision participants

\begin{tabular}{|c|c|c|}
\hline Demographic variables & $N^{\mathrm{a}}$ & $\%$ \\
\hline \multicolumn{3}{|l|}{ Age $(n=271)$} \\
\hline 18-29 years & 99 & $37 \%$ \\
\hline $30-59$ years & 130 & $48 \%$ \\
\hline 60 or older & 42 & $15 \%$ \\
\hline \multicolumn{3}{|l|}{ Gender $(n=237)$} \\
\hline Male & 107 & $45 \%$ \\
\hline Female & 125 & $53 \%$ \\
\hline Not listed & 5 & $2 \%$ \\
\hline \multicolumn{3}{|l|}{ Race $(n=250)$} \\
\hline White & 199 & $80 \%$ \\
\hline Black or African American & 29 & $12 \%$ \\
\hline Asian & 8 & $3 \%$ \\
\hline Pacific Islander & 1 & $0 \%$ \\
\hline Mixed race & 9 & $4 \%$ \\
\hline Prefer not to answer & 4 & $2 \%$ \\
\hline \multicolumn{3}{|l|}{ Ethnicity/Hispanic $(n=250)$} \\
\hline Hispanic & 85 & $34 \%$ \\
\hline Non-Hispanic & 165 & $66 \%$ \\
\hline \multicolumn{3}{|l|}{ Education level $(n=246)$} \\
\hline High school, GED, or less & 37 & $15 \%$ \\
\hline Some college/vocational or technical training & 98 & $40 \%$ \\
\hline Bachelor's degree & 52 & $21 \%$ \\
\hline Graduate degree & 59 & $24 \%$ \\
\hline \multicolumn{3}{|l|}{ Household income $(n=245)$} \\
\hline Less than $\$ 20,000$ & 34 & $14 \%$ \\
\hline$\$ 20,000$ to $\$ 55,999$ & 107 & $44 \%$ \\
\hline$\$ 56,000$ to $\$ 100,000$ & 84 & $34 \%$ \\
\hline Over $\$ 100,000$ & 20 & $8 \%$ \\
\hline \multicolumn{3}{|l|}{ Residence $(n=248)$} \\
\hline Urban ("city") & 114 & $46 \%$ \\
\hline Suburban ("neighborhood outside the city") & 120 & $48 \%$ \\
\hline Rural ("in the country") & 14 & $6 \%$ \\
\hline \multicolumn{3}{|l|}{ Employment status (check all that apply) $\left(n=270^{\mathrm{b}}\right)$} \\
\hline Full-time employment & 113 & $42 \%$ \\
\hline Part-time employment & 43 & $16 \%$ \\
\hline Stay-at-home parent & 11 & $4 \%$ \\
\hline Full-time/part-time student & 30 & $11 \%$ \\
\hline Unable to work & 6 & $2 \%$ \\
\hline Other: not employed, retired, volunteer & 88 & $33 \%$ \\
\hline
\end{tabular}

\section{PMR and willingness to participate}

Ninety-eight percent of blind/low-vision participants supported conducting the PMR study described in the survey, of whom $90 \%$ said that they would participate if asked; $63 \%$ would be willing to participate for 5-10 years, and 19\% for their lifetimes. Overall, $96 \%$ agreed that " $[\mathrm{t}]$ he study could lead to better treatments, cures, and save lives." No differences were observed across racial, ethnic, and gender groups. Compared with participants with other disabilities, support for conducting the study and belief in its therapeutic promise were higher among blind participants (respectively: 98\% vs. $95 \%, p=0.0345 ; 96 \%$ vs. $89 \%, p=0.0007)$.

\section{Data provision}

Participants were asked to select from eight types of data that they would agree to provide, if they participated in the study. Most were willing to provide lifestyle information such as diet and exercise $(78 \%$ vs. $65 \%$ compared with participants with other disabilities; $p<0.0001)$; samples like urine, saliva, or hair $(76 \%$ vs. $72 \% ; p=0.1131)$; a blood sample ( $73 \%$ vs. $73 \%)$; genetic data ( $69 \%$ vs. $61 \%$; $p=0.0131)$; samples of the soil or water around their home ("environmental samples") (64\% vs. $47 \%$; $p<0.0001)$; and family history $(63 \%$ vs. $58 \%$; $p=$ 0.1338 ). Fewer blind/low-vision participants were willing to provide heart rate or daily number of steps from their Fitbit or smartphone ( $46 \%$ vs. $31 \% ; p<0.0001)$ and information from their social media accounts $(28 \%$ vs. $35 \%$; $p=0.0312)$.

\section{Data sharing and consent}

Seventy-seven percent of blind/low-vision participants agreed with the statement that "[i]f my name and contact information are removed, data and research results from my samples can be made available for anyone to use." However, consent for researchers' use of participants' data varied ("models of consent"). The largest fraction agreed that "researchers can use [my] data in all types of research studies, but only if [I am] able to see in which studies the data will be used and decide not to participate" (31\%), followed by use of participants' data "in all types of research studies" (25\%), "only if [I] give specific permission for each study" (23\%), and "only for the research study [I] choose when [I] enroll" (21\%).

When asked which types of researchers they would allow to use their samples and information, most blind/low-vision participants selected NIH researchers (78\%) and university researchers in the United States (66\%). Only a minority selected "other government researchers" (35\%), "university researchers in other countries" (29\%), and "researchers from commercial companies that develop drugs" (26\%).

\section{Engagement}

Responses to engagement questions, including comparisons with other study participants, are shown in Table 2. The overwhelming majority of our blind participants agreed that "research participants and researchers [should] be equal partners" (82\%), and most also said they would be more willing to participate "if participants helped to plan and run the 
Table 2 Engagement between blind/low-vision participants versus participants with other disabilities

\begin{tabular}{|c|c|c|c|}
\hline Engagement questions & $\begin{array}{l}\text { Blind/ } \\
\text { low- } \\
\text { vision } \\
N(\%)\end{array}$ & $\begin{array}{l}\text { Other } \\
\text { disabilities } \\
N(\%)\end{array}$ & $\begin{array}{l}P \text { value } \\
\text { (Chi-square) }\end{array}$ \\
\hline \multicolumn{4}{|c|}{$\begin{array}{l}\text { Should research participants and researchers be equal partners? } \\
(n=1231)\end{array}$} \\
\hline Yes & $207(82 \%)$ & $829(85 \%)$ & 0.253 \\
\hline No & $46(18 \%)$ & $149(15 \%)$ & \\
\hline \multicolumn{4}{|l|}{$\begin{array}{l}\text { If participants helped to plan } \\
\text { and run the study, would } \\
\text { you... }(n=1229)\end{array}$} \\
\hline Be more willing to participate & $166(66 \%)$ & $696(71 \%)$ & $<0.0001$ \\
\hline Be less willing to participate & $30(12 \%)$ & $179(18 \%)$ & \\
\hline It doesn't matter & $57(23 \%)$ & $101(10 \%)$ & \\
\hline \multicolumn{4}{|l|}{$\begin{array}{l}\text { If you had the chance, how } \\
\text { would you want to } \\
\text { participate? (Select all that } \\
\text { apply) ( } n=1294)\end{array}$} \\
\hline Help design the study & $116(43 \%)$ & $535(52 \%)$ & 0.006 \\
\hline $\begin{array}{l}\text { Help choose research } \\
\text { questions }\end{array}$ & $169(62 \%)$ & $547(53 \%)$ & 0.009 \\
\hline $\begin{array}{l}\text { Help decide what kinds of } \\
\text { research are conducted }\end{array}$ & $120(44 \%)$ & $504(49 \%)$ & 0.144 \\
\hline $\begin{array}{l}\text { Help recruit other } \\
\text { participants }\end{array}$ & $93(34 \%)$ & $444(43 \%)$ & 0.007 \\
\hline Help collect study data & $102(38 \%)$ & $452(44 \%)$ & 0.053 \\
\hline Help analyze the data & $76(28 \%)$ & $349(34 \%)$ & 0.059 \\
\hline $\begin{array}{l}\text { Help decide what to do with } \\
\text { study results }\end{array}$ & $100(37 \%)$ & $217(21 \%)$ & $<0.0001$ \\
\hline
\end{tabular}

study" (66\%). Engagement in determining study priorities was most important to blind participants: $62 \%$ wanted to "help choose research questions" (more than other study participants [53\%]; $p=0.0088$ ), followed by "help decide what kinds of research are conducted" (44\%). blind/low-vision participants were also more likely to want to "help decide what to do with study results" ( $37 \%$ vs. $21 \%$; $p<0.0001$ ).

\section{Barriers to participation}

Participants were asked to "select all that apply" from a list of barriers that "may stop you from participating in the study" (Table 3). Responses most frequently endorsed by blind/lowvision participants were "transportation to health-care facilities is difficult" (55\%), "the space and equipment in clinics and health-care facilities are not accessible for me" (50\%), "information about medical research is not accessible to me" (43\%), "my health insurance may not cover the costs" (39\%), and "transportation to health-care facilities is too expensive" (38\%). About a third of blind/low-vision participants indicated that researchers and health-care providers "have stereotypes about people with disabilities" (36\%; higher than
Table 3 Perceived barriers to participation (by order of endorsement) by blind/low-vision participants versus participants with other disabilities

\begin{tabular}{|c|c|c|c|}
\hline $\begin{array}{l}\text { What may stop you from } \\
\text { participating in the study? } \\
\text { (Select all that apply) } \\
(n=1294)\end{array}$ & $\begin{array}{l}\text { Blind/ } \\
\text { low- } \\
\text { vision }\end{array}$ & $\begin{array}{l}\text { Other } \\
\text { disabilities }\end{array}$ & (Chi-square) \\
\hline $\begin{array}{l}\text { Transportation to health- } \\
\text { care facilities is difficult }\end{array}$ & $148(55 \%)$ & $537(52 \%)$ & 0.534 \\
\hline $\begin{array}{l}\text { The space and equipment in } \\
\text { clinics and health-care } \\
\text { facilities are not } \\
\text { accessible for me }\end{array}$ & $135(50 \%)$ & $592(58 \%)$ & 0.018 \\
\hline $\begin{array}{l}\text { Information about medical } \\
\text { research is not } \\
\text { accessible to me }\end{array}$ & $117(43 \%)$ & $445(43 \%)$ & 0.923 \\
\hline $\begin{array}{l}\text { My health insurance may not } \\
\text { cover the costs }\end{array}$ & $105(39 \%)$ & $250(24 \%)$ & $<0.0001$ \\
\hline $\begin{array}{l}\text { Transportation to health- } \\
\text { care facilities is too expensive }\end{array}$ & $102(38 \%)$ & $423(41 \%)$ & 0.269 \\
\hline $\begin{array}{l}\text { Researchers and health-care } \\
\text { providers have stereotypes } \\
\text { about people with } \\
\text { disabilities }\end{array}$ & $91(34 \%)$ & $233(23 \%)$ & 0.0003 \\
\hline $\begin{array}{l}\text { Researchers and health-care } \\
\text { providers lack knowledge of } \\
\text { my needs }\end{array}$ & $80(30 \%)$ & 436 (43\%) & $<0.0001$ \\
\hline $\begin{array}{l}\text { Research may be used for } \\
\text { studies I don't approve of }\end{array}$ & $71(26 \%)$ & 451 (44\%) & $<0.0001$ \\
\hline $\begin{array}{l}\text { Precision medicine research } \\
\text { might be used to harm } \\
\text { people like me }\end{array}$ & $69(25 \%)$ & $469(46 \%)$ & $<0.0001$ \\
\hline $\begin{array}{l}\text { I have medical problems that } \\
\text { would make it hard for me } \\
\text { to participate }\end{array}$ & $61(23 \%)$ & $323(32 \%)$ & 0.004 \\
\hline $\begin{array}{l}\text { Communication with health } \\
\text { professionals is } \\
\text { difficult for me }\end{array}$ & $47(17 \%)$ & $526(51 \%)$ & $<0.0001$ \\
\hline $\begin{array}{l}\text { I can't take time off from } \\
\text { work to participate }\end{array}$ & $44(16 \%)$ & $128(13 \%)$ & 0.108 \\
\hline $\begin{array}{l}\text { Precision medicine research } \\
\text { will not help people like me }\end{array}$ & $37(14 \%)$ & $377(37 \%)$ & $<0.0001$ \\
\hline $\begin{array}{l}\text { Precision medicine research } \\
\text { will increase stigma }\end{array}$ & $28(10 \%)$ & $125(12 \%)$ & 0.392 \\
\hline $\begin{array}{l}\text { My family or legal guardian } \\
\text { would not want me to } \\
\text { participate }\end{array}$ & $20(7 \%)$ & $214(21 \%)$ & $<0.0001$ \\
\hline $\begin{array}{l}\text { I don't have regular access to } \\
\text { the Internet }\end{array}$ & $16(6 \%)$ & $201(20 \%)$ & $<0.0001$ \\
\hline
\end{tabular}

other participants: $23 \%, p=0.0003)$ and "lack knowledge of my needs" (30\%). Fewer endorsed concerns that "research may be used for studies I don't approve of" (26\%), their medical problems could impede participation (23\%), or PMR 
"might be used to harm people like me" (25\%) and will increase stigma (10\%). Although some barriers were experienced similar to (e.g., transportation) or less than (e.g., communication difficulties) other study participants, the total number of barriers selected by blind/low-vision participants was high: $15 \%$ reported $1-2$ barriers (24.7\%) and $65 \%$ identified 3-6 barriers.

\section{DISCUSSION}

PMR studies increasingly are seeking to engage diverse communities, for which including blind/low-vision people and others with disabilities will be key. The success of this effort will depend on the views of blind people about PMR and the removal of obstacles to their engagement. Our findings suggest high levels of interest in PMR but also many concerns about barriers to participation.

Blind participants-more than other study participantsoverwhelmingly supported PMR. They expressed strong belief in its potential therapeutic benefits and were highly interested in extended participation. Notably, this enthusiasm for PMR is substantially higher than the already-high positive responses found in a previous survey of the general US adult population. ${ }^{16}$ A majority of our blind participants further indicated willingness-often more than other study participants-to provide the three key data types needed for PMR: medical and biological information (i.e., family history, genetic data, biological samples), environmental samples, and lifestyle information, though they were reluctant to provide data that are more time-consuming to report or that evoke concerns over excessive surveillance, i.e., exercise data from Fitbits or smartphones and data from social media accounts.

Most of our blind/low-vision participants would provide broad consent for uses of their data (including those who conditioned consent on the option to opt out) and data sharing with $\mathrm{NIH}$ and university researchers. This willingness may be reassuring for national and university-based PMR programs. However, almost a quarter of participants wanted to provide consent for data use on a study-by-study basis, and most participants expressed reluctance to share data with other entities. Indeed, a majority of participants were not willing to share their data with other government researchers $(65 \%)$, university researchers in other countries (71\%) and, in particular, researchers with pharmaceutical companies (74\%). While the vagueness of "other government researchers" may partially explain this finding (e.g., would it include law enforcement?), the reluctance to share data with foreign and commercial researchers requires further exploration. Suspicion of pharmaceutical companies may arise from practices such as exorbitant drug pricing and from failures specific to the blind community, such as inaccessible labeling (without braille or large print). ${ }^{17}$ This reluctance may raise challenges for the extensive public-private collaborations that PMR initiatives often require. Measures to address this may include creating processes to share the financial benefits of product development and greater attention to the specific needs of the blind community.

Notwithstanding the overall excitement about PMR among members of the blind/low-vision community, participants also identified multiple barriers to participation that, if unaddressed, will likely limit enrollment. These barriers largely mirror ones previously identified as key for blind/ low-vision people (and other people with disabilities) in health-care settings: ${ }^{18-20}$ inaccessible transportation, ${ }^{18,21}$ information, ${ }^{17,22}$ and physical facilities, ${ }^{23}$ along with stereotypes among physicians and office staff and lack of training and awareness on working with blind individuals. ${ }^{20}$ The impact of other concerns on participation in PMR (i.e., unapproved studies, harm, and stigma) is unclear. Similar concerns about promoting eugenics and other group harms were raised in studies of racial/ethnic minorities, though direct comparisons are complicated by inconsistent findings and differences in framing of questions about harms and study context (i.e., PMR vs. genetic testing/biobanking). ${ }^{24,25}$ Further exploration of the basis for concerns about PMR leading to eugenic efforts or other group harms, especially among blind people from racial/ethnic minorities (too few in our sample), is merited.

Still, the combination of barriers cited is worrisome, first, because of their high prevalence, and second, because our respondents overall were more educated and wealthier than the average blind person in the United States ( $45 \%$ of our participants had bachelor's or graduate degrees, compared with $16 \%$ among the general blind/low-vision population; $42 \%$ reported household income of $>\$ 56,000$, compared with a median of $\$ 41,000$ for adults with visual disability). ${ }^{15}$ Less educated and poorer individuals will likely face even more barriers to participation. A systematic approach to address the many barriers is clearly needed for the full inclusion of blind people in PMR.

Designing inclusive PMR studies not only benefits the field by increasing the diversity of study cohorts but ensures compliance with US law. The Americans with Disabilities Act (ADA) forbids discrimination on the basis of disability in public life, which includes ensuring accessibility, and applies to both government entities and private places of public accommodation, including universities and hospitals. ${ }^{26}$ Research initiatives run at these facilities, including private-public partnerships, are thus subject to ADA requirements. Additionally, Section 504 of the Rehabilitation Act forbids discrimination on the basis of disability in any organization that receives federal financial assistance, a category that covers most entities conducting PMR. Thus, measures that could increase inclusivity of the blind/lowvision community in PMR include addressing the following barriers:

1. Inaccessible transportation, defined as not being able to reach the intended destination, when needed, in a reasonable amount of time. ${ }^{21}$ It encompasses 
unaffordable transportation, limited public transportation during off-hours (i.e., nights and weekends), and paratransit services that operate on rigid schedules, increasing the risk that blind participants will be stranded if an appointment runs late. ${ }^{20,21}$ Accordingly, scheduling research visits on weekends or after work may not be particularly effective for increasing research participation among blind participants. Instead, researchers can consider offering free transportation to and from research sites (including, e.g., providing transportation vouchers for taxis and/or ride-sharing reimbursement), assisting participants in identifying public transit routes to the facility, and developing more local, community-based centers for enrollment and data collection that allow potential participants to avoid travel.

2. Inaccessible clinics and facilities. Blind individuals face numerous barriers at health-care facilities. These include lack of sidewalks leading directly to the clinic; ${ }^{23}$ facilities without public transit stops in front of the building, requiring blind people to pass through parking lots or other buildings to enter the facility; ${ }^{23}$ and facilities with multiple entrances, making coordination with paratransit services difficult. ${ }^{27}$ Once inside the facility, spaces that lack braille or large print signs for identification and information about how to navigate through the facility constitute additional barriers. ${ }^{19}$ Given these barriers, it is unsurprising that $50 \%$ of our blind/low-vision participants stated that clinics and health-care facilities themselves are not accessible. Increasing accessibility to clinics and research facilities requires fairly simple adjustments: PMR staff can provide blind participants with braille or audio descriptions of the facility space and/ or arrange for study personnel to meet blind participants in an identifiable location, accompany them to the facility, and assist them with enrollment and collection of data and samples. Access to technologies that offer visual interpreter services (e.g., Be My Eyes) may similarly increase mobility independence for blind participants, though these services cannot always substitute for a human guide in unfamiliar places and may be challenging for less technologically literate participants.

3. Inaccessible information. Almost half of our blind/lowvision respondents (43\%) stated that information about medical research is not accessible to them. This finding is in line with other studies indicating that medical and research information is often unavailable in braille or audio formats. ${ }^{20,22}$ This situation is further exacerbated by health-care facilities increasingly replacing in-person communication with technology, for instance, the use of touchscreen, check-in kiosks for patient registration and to obtain and communicate information. ${ }^{28}$ Such technologies are assumed to save time and $\operatorname{cost}^{29}$ and graphical interfaces have gained popularity due to their visual appeal ${ }^{30}$. However, they are infrequently designed in consultation with blind users, making many of their graphical elements and dynamic web content inaccessible ${ }^{31}$.
These technological challenges further extend to home computer systems modified for use by blind persons. Because websites and survey interfaces tend to utilize different operating systems and screen readers, they can often be incompatible with privately owned screen readers. ${ }^{32}$ Blind individuals thus must switch from their known screen reader at home to other screen-reading programs, a process that may not be easy to navigate and that requires them to learn a new program. This challenge is further complicated because screen reader programs may work better with some browser options (e.g., Firefox) than with others. ${ }^{32}$ The use of such technologies is likely to have significant impact on the participation of blind people in PMR. PMR initiatives increasingly utilize computer-based technologies to disseminate information, obtain online consent, enroll participants into PMR cohorts, and enable ongoing engagement and return of results. Without concrete measures to rectify the identified technological barriers, online PMR recruitment and communication efforts will likely be inaccessible to many blind people, discouraging them from even trying to engage in research ${ }^{33}$.

PMR studies can take several steps to reduce these challenges. These include installing screen reader technologies on relevant public devices, including cross-modal output that uses audio or haptic cues to communicate threedimensional images to blind participants ${ }^{30}$ and providing earphones for privacy; designing user interfaces that are structured in a blind-accessible way (e.g., an entirely textbased linear layout without graphics that can be read by screen readers), ${ }^{30}$ including adherence to the recommendations made by the World Wide Web Consortium for ensuring web content accessibility; ${ }^{34}$ and supplying blind participants with a tablet with screen reader software for their use, which would allow for long-term engagement in studies.

4. Attitudinal and institutional barriers. A large minority of our blind respondents expressed concerns that researchers held stereotypes about people with disabilities $(36 \%)$ and that researchers lacked knowledge of their needs (30\%). These responses are unsurprising given previous research on how unpleasant health-care experiences can be for blind individuals. ${ }^{20,35}$ Educating health professionals and researchers about the blind community and encouraging professionals' self-reflection on their own biases about blind people would be a first step. Thus, it is key for PMR personnel to be aware of privacy concerns, especially given participants' visual disabilities; to ask for individuals' preferences about how to be assisted in navigating space and technologies (e.g., receiving verbal directions, led audibly, or led by physical touch); ${ }^{20}$ and to work with blind experts to ensure that PMR is accessible for blind users. Developing a protocol for engagement and working with blind people as equal partners can facilitate rapportbuilding, and research institutions should require that such processes are in place. Indeed, such steps embody a core pillar of PMR-i.e., community engagement - and shift the 
historical view of people with disabilities, including blind people, primarily as subjects of study to partners and experts on their own conditions.

5. Increasing engagement. blind/low-vision participants in our study expressed high enthusiasm for serving as active and equal partners in PMR-related decisions, especially determining research priorities. Two-thirds of respondents said that they would be more willing to participate "if participants helped to plan and run the study." The blind community is ripe for engagement. Through collaboration with blind participants and organizations that represent them, remedies for barriers to inclusion can be implemented. As with other historically marginalized communities, involvement of blind participants will be key for identifying and conducting PMR that is responsive to the needs of the community.

This study has several limitations, primarily the small sample of blind/low-vision participants from racial/ethnic minorities who may have other concerns that would discourage their participation in PMR (similar to members of such communities more generally ${ }^{36-38}$ ). Our participants also had higher education, employment rates, and household incomes than the average blind/low-vision population in the United States. ${ }^{15}$ Although underrepresentation of participants with lower socioeconomic status is common in medical studies, ${ }^{16}$ it may have skewed the results to be more supportive of PMR. For example, higher education has been found to correlate with greater interest and willingness to participate in PMR; ${ }^{39}$ however, no such correlation was found in this study. Finally, our method of recruitment-an online survey, circulated through listservs of organizations of people with disabilitiesis likely to have excluded blind (and other) participants who do not have access to the Internet or who are not involved with such organizations. Future research should focus more specifically on the racial, ethnic, socioeconomic, and other groups that were not sufficiently included in this study.

Our study is nonetheless highly informative for PMR. It explores the views of a previously unstudied population-i.e., blind people and people with low vision-on PMR. The challenges of inaccessible transportation, information, and facilities, as well as the other attitudinal, institutional, and economic barriers identified in this study are likely to be relevant for members of the blind community across racial, ethnic, and socioeconomic groups, for whom health disparities and accessibility issues are often compounded. ${ }^{40}$ Besides highlighting the need to remove these barriers to inclusive PMR, our findings demonstrate the interest of the blind community in involvement and engagement as equal partners in PMR-related decisions. If PMR is indeed to provide the future health-care model for the United States, researchers must ensure that historically underrepresented communities with disabilities are included and thus able to reap the potential benefits. Learning about the views of these communities is the first step toward implementing inclusive practices and developing long-term relationships and engagement opportunities.

\section{SUPPLEMENTARY INFORMATION}

The online version of this article (https://doi.org/10.1038/s41436019-0533-y) contains supplementary material, which is available to authorized users.

\section{ACKNOWLEDGEMENTS}

This work was supported by National Human Genome Research Institute (NHGRI) grant K01HG008653, NHGRI/All of Us Research Program grant 3P50HG007257-05S1, and NIH Office of the Director (OD). We gratefully acknowledge the support of the Association of University Centers on Disabilities (AUCD), the National Council on Independent Living (NCIL), National Federation of the Blind (NFB), the National Association of the Deaf (NAD), and the American Association of Health and Disability (AAHD), which assisted with recruitment, survey material, and programming. We also gratefully acknowledge the support of individuals who assisted in this process: Howard A. Rosenblum, Lizzie Sorkin, Abiodun Ramroop, Dawn Rudolph, Kelly Buckland, Cara Liebowitz, Mark Starford, Marcia Orland, Kecia Brooke Weller, Charlene Jones, Roberta Carlin, Kathy Guernsey, Carlos Ríos Espinosa, Anthony Stephens (American Council of the Blind), Amar D. Mandavia, and Dave Kaufman. Finally, we thank the numerous individuals who took the time to participate in our study.

\section{DISCLOSURE}

M.S. is a member of the All of Us Research Program's Institutional Review Board. The other authors declare no conflicts of interest.

Publisher's note: Springer Nature remains neutral with regard to jurisdictional claims in published maps and institutional affiliations.

\section{REFERENCES}

1. National Institutes of Health. All of Us Research Program. 2018. https:// allofus.nih.gov/.

2. Krahn GL, Walker DK, Correa-De-Araujo RM. Persons with disabilities as an unrecognized health disparity Population. Am J Public Health. 2015;105(S2):S198-S206.

3. Sabatello M, Appelbaum PS. The precision medicine nation. Hastings Center Report. 2017;47:19-29.

4. Courtney-Long EA, Carroll DD, Zhang QC, Stevens AC, Griffin- Blake S, et. al. Prevalence of Disability and Disability Type Among Adults-United States. 2013:64;777-783.

5. National Center for Health Statistics. Table A-6a: Age-adjusted percentages (with standard errors) of hearing trouble, vision trouble, and absence of teeth among adults aged 18 and over, by selected characteristics: United States, 2017, in Summary Health Statistics. 2017. Centers for Disease Control and Prevention. https://ftp.cdc.gov/pub/ Health_Statistics/NCHS/NHIS/SHS/2017_SHS_Table_A-6.pdf. Accessed 10 May 2019

6. American Foundation for the Blind. Research Navigator: Just how many blind folks are there anyway? https://www.afb.org/newsletters/ directconnect-newsletter/research-navigator-just-how-many-blind-folksare-there-anyway. Accessed 10 May 2019.

7. Centers for Disease Control and Prevention. Vision health initiative: projection studies. 2017. https://www.cdc.gov/visionhealth/projects/ projection-studies.html. Accessed 10 May 2019.

8. Crews JE, Chou CF, Sekar S, Saaddine JB. The prevalence of chronic conditions and poor health among people with and without vision impairment, aged $\geq 65$ years, 2010-2014. Am J Ophthalmol. 2017;182:18-30. 
9. Maurer M. Jacobus tenBroek Law Symposium keynote address. Texas Civ Liberties Civ Rights. 2008;13:157-166.

10. Williams G. Theorizing disability. In: Albrecht GL, Seelman K, Bury M, eds. Handbook of disability studies. Thousand Oaks, CA: SAGE Publications; 2001. p. 123-144

11. Braddock DL, Parish SL. An institutional history of disability. In: Albrecht GL, Seelman K, Bury M, eds. Handbook of disability studies. Thousand Oaks, CA: SAGE Publications; 2001. p. 11-68.

12. Bong C, Potrata B, Hewison J, McKibbin M. Attitudes of patients and relatives/carers towards genetic testing for inherited retinal disease. Eye. 2010;24:1622-1625.

13. Mezer E, Babul-Hirji R, Wise R, et al. Attitudes regarding predictive testing for retinitis pigmentosa. Ophthalmic Genet. 2007;28:9-15.

14. Sabatello $M$, Chen $Y$, Zhang $Y$, Appelbaum PS. Disability inclusion in precision medicine research: a first national survey. Genet Med. 2019 Mar 22; https://doi.org/10.1038/s41436-019-0486-1 [Epub ahead of print].

15. Lisa Yang K, Hock E. Tan Institute on Employment and Disability Collection. Disability statistics. 2016. https://digitalcommons.ilr.cornell. edu/edicollect/. Accessed 10 May 2019.

16. Kaufman DJ, Baker R, Milner LC, et al. A survey of U.S. adults' opinions about conduct of a nationwide Precision Medicine Initiative ${ }^{\circledR}$ Cohort Study of genes and environment. PLoS One. 2016;11:e0160461.

17. Equal Rights Center. III-prepared: health care's barriers for people with disabilities. 2011. http://www.tilrc.org/assests/news/publications/erc_illprepared_report_11-11.pdf. Accessed 10 May 2019.

18. Crudden A, McDonnall MC, Hierholzer A. Transportation: an electronic survey of persons who are blind or have low vision. J Vis Impair Blind. 2015;109:445

19. Story MF, Schwier E, Kailes Jl. Perspectives of patients with disabilities on the accessibility of medical equipment: examination tables, imaging equipment, medical chairs, and weight scales. Disabil Health J. 2009;2:169-179 e1.

20. O'Day BL, Killeen M, lezzoni LI. Improving health care experiences of persons who are blind or have low vision: suggestions from focus groups. Am J Med Qual. 2004;19:193-200.

21. Bezyak JL, Sabella SA, Gattis RH. Public transportation: an investigation of barriers for people with disabilities. J Disabil Policy Stud. 2017;28:52-60.

22. Thurston $M$, Thurston A. Risks to client confidentiality when communicating health information to blind and partially sighted persons. Disabil CBR Incl Dev. 2013;24:22-40.

23. Crudden A. Transportation issues: Perspectives of orientation and mobility providers. J Vis Impair Blind. 2015;109:457-468.

24. Laskey SL, Williams J, Pierre-Louis J, et al. Attitudes of African American premedical students toward genetic testing and screening. Genet Med. 2003;5:49-54.

25. Thompson HS, Valdimarsdottir HB, Jandorf L, Redd W. Perceived disadvantages and concerns about abuses of genetic testing for cancer risk: differences across African American, Latina and Caucasian women. Patient Educ Couns. 2003;51:217-227.

26. Americans with Disabilities Act of 1990. 42 U.S. Code $\S 12101$.

27. Sharts-Hopko NC, Smeltzer S, Ott BB, et al. Healthcare experiences of women with visual impairment. Clin Nurse Spec. 2010;24: 149-153.

28. Jones R. The role of health kiosks in 2009: literature and informant review. Int J Environ Res Public Health. 2009;6:1818-1855.

29. Yvonne Chan Y-F, Nagurka R, Bentley S, et al. Medical utilization of kiosks in the delivery of patient education: a systematic review. Health Promot Perspect. 2014;4:1-8.

30. Leuthold S, Bargas-Avila JA, Opwis K. Beyond web content accessibility guidelines: design of enhanced text user interfaces for blind internet users. Int J Hum Comput Stud. 2008;66:257-270.

31. Gottliebson D, Layton N, Wilson E. Comparative effectiveness report: online survey tools. Disabil Rehabil Assist Technol. 2010;5:401-410.

32. Billah SM, Ashok V, Porter DE, Ramakrishnan IV. Ubiquitous accessibility for people with visual impairments: are we there yet? Proc SIGCHI Conf Hum Factor Comput Syst. 2017;2017:5862-5868.

33. Sabatello M. Precision medicine, health disparities, and ethics: the case for disability inclusion. Genet Med. 2018:20:397-399.

34. Accessibility Guidelines Working Group. Web content accessibility guidelines (WCAG) 2.1. 2018. http://Www.w3.org/TR/WCAG21/. Accessed 10 May 2019.

35. lezzoni LI, Davis RB, Soukup J, O'Day B. Quality dimensions that most concern people with physical and sensory disabilities. Arch Intern Med. 2003;163:2085-2092.

36. Kerasidou A. Trust me, I'm a researcher!: the role of trust in biomedical research. Med Health Care Philos. 2017;20:43-50.

37. Bentley $A R$, Callier $S$, Rotimi CN. Diversity and inclusion in genomic research: why the uneven progress? J Community Genet. 2017;8: 255-266.

38. Halbert $\mathrm{CH}, \mathrm{McDonald} \mathrm{J,} \mathrm{Vadaparampil} \mathrm{S}$, et al. Conducting precision medicine research with African Americans. PLoS One. 2016;11: e0154850.

39. Kaufman D, Murphy J, Scott J, Hudson K. Subjects matter: a survey of public opinions about a large genetic cohort study. Genet Med. 2008;10:831-839.

40. Yee S, Breslin M-L, Goode TD, et al., Compounded disparities: health equity at the intersection of disability, race, and ethnicity. 2018. The National Academies of Sciences, Engineering, and Medicine. http:// nationalacademies.org/hmd/ /media/Files/Activity\%20Files/SelectPops/ HealthDisparities/Commissioned\%20Papers\%20and\%20Perspectives/ Compounded\%20Disparities\%20-\%20Intersection\%20of\% 20Disabilities\%20Race\%20and\%20Ethnicity.pdf. Accessed 10 May 2019. 